\title{
Partnership between Primary Health and Social Care Services in the Long-Term Care of Older People with Dementia: A Vignette Study
}

Ausrine Kontrimiene ( $\nabla$ ausrine.kontrimiene@lsmuni.lt)

Lithuanian University of Health Sciences https:// orcid.org/0000-0003-2880-2307

\section{Aurelija Blazeviciene}

Lietuvos sveikatos mokslu universitetas

\section{Ida Liseckiene}

Lietuvos sveikatos mokslu universitetas

\section{Gediminas Raila}

Lietuvos sveikatos mokslu universitetas

\section{Leonas Valius}

Lietuvos sveikatos mokslu universitetas

\section{Lina Jaruseviciene}

Lietuvos sveikatos mokslu universitetas

\section{Research article}

Keywords: primary health care, mental health services, social work, long-term care, patient care, health personnel, dementia

Posted Date: October 1st, 2020

DOl: https://doi.org/10.21203/rs.3.rs-74165/v1

License: (9) This work is licensed under a Creative Commons Attribution 4.0 International License. Read Full License

Version of Record: A version of this preprint was published at INQUIRY: The Journal of Health Care Organization, Provision, and Financing on January 1st, 2021. See the published version at https://doi.org/10.1177/00469580211011933. 


\section{Abstract}

Background. Dementia is considered to be a significant cause of disability and dependency for older people worldwide and it raises difficulties in providing adequate formal and informal assistance. Research on the experience of long-term care (LTC) services for older people with dementia is scarce in Eastern European countries. This study aimed to understand the system of care for older people with dementia from the perspective of health and social care workers providing LTC services in Lithuania.

Methods. A total of 72 primary health care and social care professionals from public and private institutions in Kaunas city participated in this study. One-to-one interviews were conducted with family physicians, community nurses, psychiatrists, psychiatric nurses, and social workers. A vignette situation of two fictitious patients with dementia and their informal caregiver was discussed during the interviews. Data were analyzed using thematic analysis by induction approach.

Results. Thematic analysis of the data revealed two main themes: LTC provision trajectory, and threedimensional relationship perception in realization of LTC activities. LTC provision trajectory reflected activities performed as a response to the described situation embracing formal procedures for the endorsement of LTC needs as well as the range of LTC services. Three-dimensional relationship perception in realization of LTC activities mirrored the participants' relationships with themselves, with each other, and with the informal caregiver.

Conclusions. Our study revealed the potential of complex measures that could be instrumental for the refinement of the caregiving process. First, a change in the special needs' endorsement logic is needed, shifting focus from medical diagnosis to functional abilities assessment. Second, establishing clear procedures for formal cooperation between the health and social care sectors in the trajectory of LTC service provision. Finally, finding an adequate balance between LTC and institutional care by creating a wider range of LTC services. A more consistent and coordinated delivery of services by both health and social care sectors seems to be an untapped resource for the improvement of the LTC potential.

\section{Background}

Aging population dramatically challenges the socio-economic, health, and social care areas of the Western societies of middle- and high-income countries [1]. Multiple chronic conditions, including dementia are present in approximately $80 \%$ of older adults creating increasing pressure on care systems worldwide [2]. Dementia is seen as a significant cause of disability and dependency in older people, which also has a profound impact on the lives of their families and communities [3, 4]. It is estimated that the number of people living with dementia worldwide is currently over 50 million and may increase up to 152 million by 2050 [5]. This creates a significant economic burden of dementia care on patients, their informal caregivers, and health care systems [6]. However, it is nursing and informal care, and not the direct medical costs, that contribute the most to the total care costs of patients with dementia (e.g., 
home-based long-term care (LTC), nursing homes) [4, 6]. Furthermore, it negatively affects the work efficiency and employability of the informal caregivers in the labor market $[4,6]$.

Research suggests that patients with complex LTC needs experience multiple parallel care processes, which may have conflicting or competing goals within their individual patient trajectories [7]. Thus, the reorganization of social and health care processes focusing on dementia patients has become one of the top priorities across countries, and a large array of tools, including attitudinal, organizational, and regulatory transformation of care delivery, have been applied with the aim to foster integrated service delivery [3,7-10]. Studies indicate that a partnership between health care and social services results in higher user satisfaction with the care received [11, 12], and lower avoidable health care use and spending [13]. However, different collaborative actions and frameworks of integrated care are being discussed to meet the needs of country-specific health and social care systems, taking into account the cultural and national aspects of the systems [14-16].

Fragmentation of health and social care in providing LTC remains an alarming issue in Lithuania. Previous legislative attempts to foster collaboration between these sectors, such as funding of joint activities, had a low impact on service provision and left organizational frameworks unchanged $[17,18]$. Lack of collaboration is especially detrimental in the context of financial strain-spending on social protection per person in Lithuania barely reaches half of the EU average [19]; the health expenditure in the financial year 2017 accounted for $6.5 \%$ of the GDP, which was substantially lower than the EU average of 9.8\% [20]. Health care spending on LTC is 7.9\% below the EU average [20]. The demand for both institutional and home care provision widely exceeds the supply [21], and as a consequence, the number of avoidable hospitalizations is high [22]. The financial expression of these circumstances was illustratively reflected in a previous research comparing the cost of dementia in different regions of the world: the direct social cost of dementia in Eastern Europe (EE) is relatively low (20.7\%) as compared to the global mean (40.1\%); however, health care and informal care are comparatively overloaded (direct health care costs in EE were $24.1 \%$ compared to the global mean of $19.5 \%$; informal care costs in EE were $55.2 \%$ compared to the global mean of $40.4 \%$ ) [23].

Lack of partnership and coordination of care activities between health and social care sectors could negatively affect the well-being and safety of older patients with dementia and impose an additional burden on their informal caregivers $[24,25]$. Various efforts have been made to address the Lithuanian situation of care for older patients with complex needs including dementia, mainly focusing on the experience of informal caregivers [26, 27], piloting the integrated care delivery project [28, 29]. However, research on long term care for older patients with complex needs is missing not only in Lithuania, but also in other Eastern European countries [21,30]. Therefore, this study aimed to bridge this research gap, assessing the partnership between the formal caregivers from health care and social sectors providing LTC services for the older patients with dementia in Lithuania.

\section{Methods}


This study is a part of a larger project titled "Integrated Health Care for Senior's Mental Health: Developing an Intersectoral Cooperative Care Model." The three-year project (2017-2020) is financed by the Lithuanian Research Council (S-MIP-17-121). The aim of the project is to develop a better understanding of the primary health care and social care collaboration and management of older people with mental disorders and their informal caregivers, and to find pathways for improvement in care. The views regarding the care system held by the informal caregivers attending to elderly patients with mental disorders have been discussed elsewhere [31]. The focus of this study was to understand the system of care for older patients with dementia in Lithuania from the perspectives of family physicians (FPs), community nurses (CNs), psychiatrists (PPs), psychiatric nurses (PNs), and social workers (SWs).

The Regional Committee on Biomedical Research Ethics of Kaunas approved this study on 2018-04-23 (No:BE-2-47).

\section{Context of Lithuanian health care and social care systems}

Lithuanian primary health care consists of public and private primary health care centers, which work under agreement with the National Sickness Fund (NSF) and provide free of charge services to the patients. The main PHC providers are family physicians and community nurses, and the main providers of primary psychiatric care are psychiatrists, psychiatric nurses, social workers, and psychologists. The special needs of the older people in Lithuania are of two types: permanent care and permanent nursing. Both types of special needs provide different levels of financial benefits, reimbursement of medicines and technical assistance devices, and the provision of health and social care services including LTC, provided by community nurses on incentivized basis. Home social care services are provided through social service centers owned by the municipalities. Health care services are free of charge while social care services require co-payment.

\section{Study design}

A vignette study method was chosen to get a deeper understanding of the viewpoint of the different professionals involved in the care of the older people with dementia. The theoretical framework of the vignette investigation had two main elements: professional practice experience at the micro level (i.e., formal procedures, range of functions, and challenges in formal caregiving) and intersectoral collaboration trajectory (i.e., pathways of partnership between sectors and challenges of mutual collaboration). We chose the vignette method as it allows for better insights into the micro level of health and social care systems and reveals the personal experiences of professionals engaged in the processes of care.

A vignette situation involving two fictitious patients (spouses) with dementia and their daughter was created by our group of researchers based on a previous research with informal caregivers [26] and the opinions of experts. The vignette was piloted with a group of experts, which included all the professions to be included later in the study, that is, family physicians, community nurses, psychiatrists, psychiatric nurse, and social worker. Revisions were made to the vignette based on their feedback. The final version 
of the vignette was approved by both the experts and the researchers. Five open-ended questions to be presented following the situation were prepared for the participants (Table 1). All participants signed informed consent forms and were informed about the course of the study. Participants were provided with information on confidentiality and the opportunity to withdraw from the study at any time.

Table 1

Question for the vignette situation

1. What would you identify as the main problems in this situation?

2. How do you usually find out about this situation?

3. How would you deal with this case: what would you do during this visit?

4. How would you deal with this case: what would be your long-term care plan?

5 . What is your experience with other professionals in dealing with such situations?

\section{Data collection}

The study was conducted in Kaunas, which is a highly urbanized central city in Lithuania. The data was collected during the spring and summer of 2019. Primary health care professionals from public and private clinics of Kaunas city were invited to participate in the study. Snowball sampling was used to invite professionals from different practices who were willing to participate in the study.

Four researchers specially trained in qualitative data gathering conducted the interviews. Most of the interviews were handwritten, as a majority of the participants refused to be audiotaped during the interview. Therefore, we decided to increase the sample size to ensure the reliability of the data even though data saturation was achieved relatively earlier in the process of data collection.

\section{Data analysis}

Data were analyzed using thematic analysis by induction approach [32]. Two independent researchers analyzed the data and created codes, which were later combined into categories from which the main themes were formed. Discrepancies in analysis were discussed and a unanimous decision was reached between the researchers. Verbatim extracts of the participants' interview data have been used to illustrate the categories. The source of each illustration has been labeled at the end of the quote (e.g., "CN2" denotes the number of an interview with a community nurse), omitted sentences have been marked with bracketed ellipses [...], and researchers' comments have been given in brackets (e.g., [family physician]).

\section{Results}

\section{Participants}

A total of 72 participants took part in the study (Table 2), of which 68 were women. Mean age of the participants was 48 years $(S D=11.65)$. One half of the participants comprised of family physicians and community nurses ( $n=19$ and $n=18$, respectively), and the rest were psychiatrists $(n=13)$, psychiatric 
nurses $(n=10)$, and social workers $(n=12)$. The participants worked at private $(n=24)$ and public $(n=48)$ primary health care centers. The sociodemographic data of the participants are presented in Table 2.

Table 2

Sociodemographic data of the participants

\begin{tabular}{|c|c|c|}
\hline Indicator & $\mathbf{n}$ & $\%$ \\
\hline \multicolumn{3}{|l|}{ Gender } \\
\hline Female & 68 & 94.4 \\
\hline Male & 4 & 5.6 \\
\hline \multirow[t]{3}{*}{ Mean age (years) } & \multicolumn{2}{|c|}{$48(S D * 11.65)$} \\
\hline & \multicolumn{2}{|c|}{$\min 22 ; \max 70$} \\
\hline & \multicolumn{2}{|c|}{$\mathrm{IQR}^{\star \star \star} 18.75$} \\
\hline \multicolumn{3}{|l|}{ Profession } \\
\hline Family physician & 19 & 26.4 \\
\hline Community nurse & 18 & 25.0 \\
\hline Psychiatrist & 13 & 18.1 \\
\hline Social worker & 12 & 16.7 \\
\hline Psychiatric nurse & 10 & 13.9 \\
\hline \multicolumn{3}{|l|}{ Type of practice } \\
\hline Public & 48 & 66.7 \\
\hline Private & 24 & 33.3 \\
\hline Total number of participants & 72 & 100.0 \\
\hline
\end{tabular}

\section{*SD - standard deviation **IQR - interquartile range Long-term care provision trajectory}

Formal procedures for endorsement of LTC needs. The study participants of all professional profiles stressed the necessity to execute the formal application of special needs endorsement to the competent institution. Formal identification of special needs seems to be a launching mechanism of LTC services both for nursing and social care services: "We wouldn't get to these people because they don't have special nursing needs [...] we only go when they have special nursing needs [...]," SW3. However, the participants expressed that the execution of this formal requirement has exceptions in the health care sector and depends on the medical criteria. The participants expressed doubts whether the status of both the patients presented in the vignette could qualify the formal criteria for special needs endorsement. 
It is difficult for them to leave the house. Although, it is unlikely that they would be identified with special nursing needs because they are not bedridden. We have situations in the visiting care where the [functional] condition of people is very poor and special nursing needs are not established [...], SW3

Range of LTC services. The participants' experiences indicate that the formal endorsement of special needs unlocks the LTC possibilities realized by health and social care providers. The spectrum of services provided at the patient's home ranges from education of informal caregivers (performed by GPs or CNs), to assistance in medication management (performed by $\mathrm{CNs}$ ), bedsore treatment (performed by $\mathrm{CNs}$ ), and general household assistance (performed by CNs or SWs) with the involvement of municipal bodies and non-profit organizations. Institutional nursing, in contrast to home care, seems to be accessible to all patients with and without special needs endorsement. This possibility was repeatedly mentioned by all the participants as the only tangible long or short-term solution to the situation: "I would recommend inpatient treatment in a nursing hospital until a further decision is made on how to organize patient care," CN16.

\section{Three-dimensional relationship perception in realization of LTC activities}

Relationships between health and social care providers. The participants' insights revealed that cooperation between health and social care providers is weak and abstruse. Both health and social care providers admitted facing challenges for partnership, ranging from difficulties in information sharing about the particular needs of the patient to a more general non-cooperative attitude between the sectors as there is no routine feedback regarding the patient care needs from either side.

Facing organizational aspects - workers do not answer, are on holidays or business trips or on sick leaves and there is no one to replace them, you leave your contact information, but no one calls back. I ask for feedback, but it's not there. I pass on the information and you don't know what's going on, you don't get answers. There is no cooperation with the social services department, no feedback, SW1.

When there is no communication, there are no problems. We don't have a social worker, so we don't even know what they can do. We try to solve the problems together with the informal caregivers, FP3.

The following circumstances, unfolded by the participants, may underlie this non-cooperative attitude:

- Health and social care sectors are two different cultural systems fairly uninformed of each other. The participants revealed discrepancies in professional goals of health and social care providers and a lack of experience in arriving at common priorities.

They [physicians] don't have time and you feel underappreciated for the work. You try to be a professional in your field, but there is an imposition of opinion, they seem to know everything, overestimated selfesteem. Lack of cooperation, communication, different priorities, high workloads, SW1. 
- It appears that health care providers lack the knowledge of the social care sector structure and are poorly informed about social workers' roles and functions. Additionally, the providers from each sector lack contacts in the other sector and do not know where to look for them.

I tried many times to look for [a social worker] but failed. I also searched the Internet and called. They don't have enough staff and the waiting list is long. I called private ones directly. There is no feedback from public ones, FP7.

- Another aspect affecting potential cooperation between the professionals from the two sectors is attitudinal: unfriendliness and unwillingness to cooperate.

The attitude of the medics is that we are better than you. This status comes across strongly, not mildly. As if we are the lowest link. I don't feel that way. Maybe the older generation feels that way. I really don't feel inferior and interact with doctors as I do with those on my own level, but [...] when I worked in the visiting service, it really felt bad, SW4.

Doctors look down at our profession. They don't want to communicate with us; they don't come down to our level, SW3.

There are no systematic approaches that would favor a partnership between social and health care sectors on the providers' level. Social care providers indicated that individual motivation for partnership from the medical professionals' side is low, and representatives of both sectors indicated that there are no official pathways for intersectoral collaboration.

We come to an agreement with the private ones [social care providers], we cooperate very well, but it is difficult with the public ones, FP7.

They [social workers] are hard to find because they are working only in the eldership. It is not clear where exactly to call, under what circumstances it is acceptable to call, FP11.

Relationships with informal caregivers. Informal caregivers were perceived as the central figure in care organization and provision by all the participants. Health and social care providers expressed three types of reactions toward informal caregivers (the patient's daughter in the vignette situation): pressure, empathy, and guidance. All the participants underlined that the responsibility for control of the situation lies with the patient's daughter. They called it "the constitutional duty" (PPs) of the daughter to care for her parents, and intended to push her "to seek solutions" (GPs).

I prescribe medication and practically nothing more. Explain to the relatives about nursing home and special nursing needs identification. I will also explain that it is their constitutional duty to take care of their parents. I have my own grandmother who is 96 years old; we have hired help. We tried to care for her ourselves, went crazy after a week, and looked for another way, PP12. 
However, some respondents expressed a more empathetic attitude toward the informal caregiver, questioning her ability to take full responsibility for the care of her parents, stressing the need to share her perspective on the situation, and to pay attention to her personal expectations and her own needs for assistance.

Relatives also need time. All information needs to be gathered and all options considered by the relatives. Maybe there would be those who want to help. It would be good for them [patients] to live in their own home, they have their own feelings and their own experiences, who knows if they would let a stranger into the house [...], PN8.

The participants seldom pointed out the guiding information that could increase the informal caregiver's general awareness about care organization (i.e., information on where to seek assistance - CNs), or shared their competence in specific care aspects (i.e., fall prevention - GPs).

Self-relationship with LTC provision. The participants perceived the vignette situation of two older people with dementia as an overwhelming challenge triggering feelings of helplessness and frustration regarding the lack of professional possibilities for assistance, yet a responsible willingness to help.

I can't say anything good about this situation. You are powerless, PP12.

Since I've already come, I'd probably fix that ulcer. I don't know what I can do anymore, CN2.

The situation is clearly impossible to solve, because I could give all my money and that would not be enough [...], SW10.

\section{Discussion}

This study revealed challenges faced by health care and social care representatives providing services for older people with dementia in Lithuania. The main findings of our work suggest that scarcity of funding is not the sole explanation of inadequately addressed LTC needs of older people with dementia in Lithuania. Bureaucratic formalities limiting the opportunities for the provision of LTC services until the special needs are determined, a deep reliance on medical and especially on institutional care, and a lack of partnership within and between the sectors result in the helplessness of formal providers and increase the pressure on the informal caregivers.

These results are consistent with previous findings that the provision of LTC in Lithuania is heavily placed on the medical sector [23]. The participants argued that formal endorsement for LTC needs is based on medical criteria and that the endorsement procedure could solely be initiated by the health care professionals. Moreover, medical care, including in-patient care, is the only LTC possibility for patients without formal endorsement of special needs. This could explain why the health care costs for dementia in Eastern European countries exceed social care costs, while the global pattern is the complete opposite, that is, social care costs are at least twice as high as the medical costs $[5,23]$. Thus, the concerted push expressed by health care and social care service providers toward informal caregivers to take the full 
responsibility for the management of the situation revealed in our study could serve as a characteristic illustration of informal care overload in the context of low social spending on LTC.

Complex solutions must be discussed in searching for a way out from this tense situation. Increasing social spending on LTC needs should perhaps be the top priority of any political manifesto. Further, home care development to meet both medical and non-medical needs of the older people should be emphasized. Decreasing bureaucratic requirements, expansion of the spectrum of LTC services, tailoring the format of the visits to the needs of the patients, and expanding service delivery with a self care component $[33,34]$ are a few changes that could be made for a more sensitive response to the LTC needs and a more balanced distribution of the LTC burden. Well-developed home care is proven to have positive effect on lowering re-hospitalization rates, thus, diminishing medical care costs [33]. The recent legislative amendments by the Ministry of Health, considerably enlarging the home care "gates" for all the people who are in need of LTC services regardless of the presence/absence of a formal endorsement for LTC needs, could be a step forward in this direction [35]. These developments could have a positive impact on finding a balance between home care and institutional care in Lithuania.

A majority of the participants in our study discussed the opportunity of institutional care as the singular solution for older patients with dementia. The national policy enabling the possibility to receive up to 104 nursing services per year at home only in the case of a formal endorsement for special needs [35], but not applying this requirement for institutional nursing up to 120 days per year [17], embodies the intrinsic Lithuanian reliance on institutional care. Research indicates that Eastern and Southern European countries often follow this pattern, while Nordic and some Continental European countries put much more emphasis on community and home-based care [21]. However, prioritization of home care over residential care should go in line with the establishment of sufficient home-based LTC services [21].

Partnership between health care and social service providers is proven to have a positive impact on user satisfaction as well as leading to a more efficient use of the resources [13,36,37]. Leading health care positions in LTC provision revealed in our study could also be exploited in a positive way. Research indicates that greater centrality of health care organizations in collaborative networks of health care and social care services organizations results in higher performance of these networks, expressed in the form of lower avoidable health care use and spending on older adults [13].

However, the need for better coordination between social and health care sectors and the higher understanding of the social care system revealed in our study are not previously unknown issues $[38,39]$. Our data suggest that the attitude of non-cooperation between social and health care providers, and a lack of systematic approaches for efficient collaboration (e.g., uncertainties about professional roles and functions, lack of mutual formal communication pathways) hamper provisions of integrated care for patients with complex needs. Previous research indicates that a policy shift toward integration is not an easily achievable task, as individual innovators, and not legal imperatives are often the key drivers of change [8]. A study assessing the different types of collaborative ties between healthcare and social care services organizations concluded that co-sponsoring projects could be listed among the most effective 
ways of fostering effective partnerships [13]. Finally, the importance of social environment and community involvement in LTC delivery should be emphasized. Research indicates that partnerships should overstep the boundaries of formal health care and social service organizations; higher performing communities also have strong informal support networks, partnerships with faith-based organizations, grassroots organizations, and advocacy efforts [40].

\section{Limitations}

The findings of this study are based on the subjective personal insights of health care and social care professionals as a response to a specific vignette situation. Moreover, the study was conducted with professionals working in a highly urbanized setting; the experiences of professionals from rural areas may differ. Another limitation of the study could be related to the participants' subjective representations where health care sector outweighed the social services. We suggest that further studies on the subject should utilize triangulation research wherein interview data are complemented by objective observational data.

\section{Conclusions}

The present study revealed the potential factors that could have a positive impact on the caregiving process and possibly decrease the perceived difficulties of formal caregivers. Comprehensive measures summarized in following three points should be addressed when developing an LTC improvement strategy. First, facilitating the endorsement of special needs should be a priority and should not be based solely on the patient's medical condition, but rather on their functional abilities. Second, improvements should focus on the establishment of clear procedures for formal cooperation between the health care and social care sectors in the trajectory of LTC service provision, with a higher awareness of the functions and roles of the representatives of both the sectors. Finally, strengthening LTC provision should focus on a more adequate balance between home care and institutional care by creating a wider range of LTC services. A more consistent and coordinated delivery of services by both the health care and social care sectors seems to be an untapped resource for the improvement of the LTC potential.

\section{List Of Abbreviations}

CNs- community nurses

FPs - family physicians

IQR- interquartile range

LTC- long-term care

OECD-Organisation for Economic Co-operation and Development 
PHC- Primary Health Care

PNs- psychiatric nurses

PPs- psychiatrists

SD- standard deviation

SWs- social workers

WHO - World Health Organization

\section{Declarations}

\section{Ethics approval}

Regional Committee on Biomedical Research Ethics of Kaunas approved this study on 2018-04-23 (No.:BE-2-47).

\section{Consent for publication}

Not applicable

\section{Availability of data and material}

The datasets analyzed in the current study are available from the corresponding author on reasonable request.

\section{Competing Interests}

None declared.

\section{Funding}

This study was a part of the project entitled “Integrated Health Care for Senior's Mental Health:

Developing an Intersectoral Cooperative Care Model” (S-MIP-17-121), funded by the Research Council of Lithuania.

\section{Authors' contributions}

$L J, A K, I L, G R, A B$, and VL formulated the main research idea and designed the study. $A K, A B$, IL and $G R$ carried out the interviews. $L J$ and $A K$ analyzed the data. $A B, L J$ and $A K$ drafted the manuscript. $L J, A B$, GR, LV, and IL supervised and guided the study. All authors read and approved the final manuscript.

\section{Acknowledgments}


The authors thank all health care and social care professionals who kindly spared their time to take part in this study.

\section{References}

1. Alzheimer's Disease International. The World Alzheimer Report. 2018: The state of the art of dementia research: New Frontiers. Alzheimer's Disease International (ADI), London. [Internet]. 2018 [cited 2020 Jun 24]. Available from: https://www.alz.co.uk/research/WorldAlzheimerReport2018.pdf?2 [Accessed 2020-07-13].

2. Palmer K, Marengoni A, Forjaz MJ, Jureviciene E, Laatikainen T, Mammarella F, et al. Multimorbidity care model: Recommendations from the consensus meeting of the Joint Action on Chronic Diseases and Promoting Healthy Ageing across the Life Cycle (JA-CHRODIS). Health Policy Amst Neth. 2018;122(1):4-11. doi:10.1016/j.healthpol.2017.09.006.

3. Global action plan on the public health. response to dementia 2017-2025. Geneva: World Health Organization; 2017. Licence: CC BY-NC-SA 3.0 IGO.

4. Schaller S, Mauskopf J, Kriza C, Wahlster P, Kolominsky-Rabas PL. The main cost drivers in dementia: a systematic review. Int J Geriatr Psychiatry. 2015;30(2):111-29. doi:10.1002/gps.4198.

5. Alzheimer's Disease International. 2019. World Alzheimer Report 2019: Attitudes to dementia. London: Alzheimer's Disease International. [Internet]. Available from: https://www.alz.co.uk/research/world-report-2019. [Accessed 2020-07-13].

6. Michalowsky B, Thyrian JR, Eichler T, et al. Economic Analysis of Formal Care, Informal Care, and Productivity Losses in Primary Care Patients who Screened Positive for Dementia in Germany. J Alzheimers Dis. 2016;50(1):47-59. doi:10.3233/JAD-150600.

7. Berntsen GK, Gammon D, Steinsbekk A, et al. How do we deal with multiple goals for care within an individual patient trajectory? A document content analysis of health service research papers on goals for care. BMJ Open. 2015;5(12):e009403. doi:10.1136/bmjopen-2015-009403. Published 2015 Dec 10.

8. Pearson C, Watson N. Implementing health and social care integration in Scotland: Renegotiating new partnerships in changing cultures of care. Health Soc Care Community. 2018;26(3):e396-403. doi:10.1111/hsc. 12537.

9. Hendry A, Taylor A, Mercer S, Knight P. Improving Outcomes through Transformational Health and Social Care Integration - The Scottish Experience. Healthc Q. 2016;19(2):73-9. doi:10.12927/hcq.2016.24703.

10. $10.5334 / \mathrm{ijic} .3107$

van Duijn S, Zonneveld N, Lara Montero A, Minkman M, Nies H. Service Integration Across Sectors in Europe: Literature and Practice. Int J Integr Care. 2018;18(2):6. Published 2018 Apr 19. doi:10.5334/ijic.3107.

11. $10.1186 / \mathrm{s} 12913-018-3161-3$ 
Baxter S, Johnson M, Chambers D, Sutton A, Goyder E, Booth A. The effects of integrated care: a systematic review of UK and international evidence. BMC Health Serv Res. 2018;18(1):350. Published 2018 May 10. doi:10.1186/s12913-018-3161-3.

12. Stepurko T, Pavlova M, Groot W. Overall satisfaction of health care users with the quality of and access to health care services: a cross-sectional study in six Central and Eastern European countries. BMC Health Serv Res. 2016;16(a):342. doi:10.1186/s12913-016-1585-1. Published 2016 Aug 2.

13. Brewster AL, Yuan CT, Tan AX, Tangoren CG, Curry LA. Collaboration in Health Care and Social Service Networks for Older Adults: Association With Health Care Utilization Measures. Med Care. 2019;57(5):327-33. doi:10.1097/MLR.0000000000001097.

14. $10.5334 / \mathrm{ijic} .4164$

Buch MS, Kjellberg J, Holm-Petersen C Implementing Integrated Care - Lessons from the Odense Integrated Care Trial. Int J Integr Care. 2018;18(4):6. Published 2018 Oct 29. doi:10.5334/ijic.4164.

15. Briggs AM, Valentijn PP, Thiyagarajan JA, Araujo de Carvalho I. Elements of integrated care approaches for older people: a review of reviews. BMJ Open. 2018;8(4):e021194.

doi:10.1136/bmjopen-2017-021194. Published 2018 Apr 7.

16. $10.5334 / \mathrm{ijic} .3082$

Steele Gray C, Wodchis WP, Baker GR, et al. Mapping for Conceptual Clarity: Exploring Implementation of Integrated Community-Based Primary Health Care from a Whole Systems Perspective. Int J Integr Care. 2018;18(1):14. Published 2018 Mar 21. doi:10.5334/ijic.3082.

17. The Government of the Republic of Lithuania. Resolution on the approval of the list of conditions for the provision of personal health care services paid from the budget of the compulsory health insurance fund. Tar, 2014-04-28, no. 4811. [Available from: https://eseimas.Irs.It/portal/legalAct/It/TAD/1767a8d0cec711e39b2ab5bbcc4f49fb/asr] [Accessed 2020-0713].

18. Groenewegen PP, Dourgnon P, Greß S, Jurgutis A, Willems S. Strengthening weak primary care systems: steps towards stronger primary care in selected Western and Eastern European countries. Health Policy. 2013;113(1-2):170-9. doi:10.1016/j.healthpol.2013.05.024.

19. Eurostat [Internet]. European Comission. 2019. https://ec.europa.eu/eurostat/data/database. Social protection expenditure, 2019. Available form: https://ec.europa.eu/eurostat/data/database [Accessed 2020-07-13].

20. OECD/European Observatory on Health Systems and Policies. (2019), Lithuania: Country Health Profile 2019, State of Health in the EU, OECD Publishing, Paris/European Observatory on Health Systems and Policies, Brussels, https://doi.org/10.1787/35913deb-en.

21. Spasova S, Baeten R, Coster S, Ghailani D, Peña-Casas R, Vanhercke B. Challenges in long-term care in Europe. A study of national policies, European Social Policy Network (ESPN). Brussels: European Commission; 2018. doi:10.2767/84573.

22. Manderbacka K, Arffman M, Satokangas M, Keskimäki I. Regional variation of avoidable hospitalisations in a universal health care system: a register-based cohort study from Finland 1996- 
2013. BMJ Open. 2019;9(7):e029592. doi:10.1136/bmjopen-2019-029592. Published 2019 Jul 18.

23. Alzheimer's Disease International. The World Alzheimer Report. 2015: The Global Impact of Dementia. An analysis of prevalence, incidence, cost and trends. Alzheimer's Disease International (ADI), London, 2015. Available from: https://www.alz.co.uk/research/WorldAlzheimerReport2015.pdf [Accessed 2020-07-13].

24. European Union

Zigante V. Informal care in Europe- Exploring Formalisation, Availability and Quality. European Commission, European Union; 2018. [Available from: https://ec.europa.eu/social/main.jsp? catld=738\&langld=en\&publd=8106\&type=2\&furtherPubs=no] [Accessed 2020-07-13] .

25. Kirst M, Im J, Burns T, et al. What works in implementation of integrated care programs for older adults with complex needs? A realist review. Int J Qual Health Care. 2017;29(5):612-24. doi:10.1093/intqhc/mzx095.

26. Kontrimiene A, Sauseriene J, Liseckiene I, Valius L, Jaruseviciene L. Insights into the system of care of the elderly with mental disorders from the perspective of informal caregivers in Lithuania. Int $J$ Ment Health Syst. 2019;13:55. doi:10.1186/s13033-019-0311-x. Published 2019 Aug 13.

27. Akgun-Citak E, Attepe-Ozden S, Vaskelyte A, et al. Challenges and needs of informal caregivers in elderly care: Qualitative research in four European countries, the TRACE project. Arch Gerontol Geriatr. 2020;87:103971. doi:10.1016/j.archger.2019.103971.

28. $10.5334 /$ ijic.2509

Jurkuvienè R, Danusevičienè L, Butkevičienè R, Gajdosikienè I. The Process of Creating Integrated Home Care in Lithuania: from Idea to Reality. Int J Integr Care. 2016;16(3):8. Published 2016 Aug 19. doi:10.5334/ijic.2509.

29. Kudukytè-Gaspere R, Jankauskienė D. The Integrated Health Care Services: People-Centered Health Care in European Region [In Lithuanian]. Health Policy Manag. 2014;2(7):113-33. [Available from: https://www3.mruni.eu/ojs/health-policy-and-management/article/view/3910] [Accessed 2020-0713].

30. Genet N, Boerma WG, Kringos DS, et al. Home care in Europe: a systematic literature review. BMC Health Serv Res. 2011;11:207. doi:10.1186/1472-6963-11-207. Published 2011 Aug 30.

31. 10.1186/s13033-019-0311-x

Kontrimiene A, Sauseriene J, Liseckiene I, Valius L, Jaruseviciene L. Insights into the system of care of the elderly with mental disorders from the perspective of informal caregivers in Lithuania. Int $J$ Ment Health Syst. 2019;13:55. Published 2019 Aug 13. doi:10.1186/s13033-019-0311-x.

32. Braun V, Clarke V. Using thematic analysis in psychology. Qual Res Psychol. 2006;1(2):77-101. DOI:10.1191/1478088706qp063oa. 3 ) .

33. Irani $\mathrm{E}$, Hirschman KB, Cacchione PZ, Bowles $\mathrm{KH}$. Home health nurse decision-making regarding visit intensity planning for newly admitted patients: a qualitative descriptive study. Home Health Care Serv Q. 2018;37(3):211-31. doi:10.1080/01621424.2018.1456997. 
34. Gillard S, Adams K, Edwards C, et al. Informing the development of services supporting self-care for severe, long term mental health conditions: a mixed method study of community based mental health initiatives in England. BMC Health Serv Res. 2012;12:189. doi:10.1186/1472-6963-12-189. Published 2012 Jul 7.

35. Ministry of Health of the Republic of Lithuania. On order of the Minister of Health of the Republic of Lithuania of 14 December 2007 no. Amendment v-1026 "Approval of the description of the requirements for the provision of services at home" [In Lithuanian]. Tar, jun 3, 2020, no. 12046. [Available from: https://www.e-tar.lt/portal/en/legalAct/d2942be0a56411ea9515f752ff221ec9] [Accessed 2020-07-13].

36. Petch A, Cook A, Miller E. Partnership working and outcomes: do health and social care partnerships deliver for users and carers? Health Soc Care Community. 2013;21(6):623-33. doi:10.1111/hsc. 12050 .

37. Rummery K. Healthy partnerships, healthy citizens? An international review of partnerships in health and social care and patient/user outcomes. Soc Sci Med. 2009;69(12):1797-804. doi:10.1016/j.socscimed.2009.09.004.

38. 10.1186/s12913-018-2889-0

Carter N, Valaitis RK, Lam A, Feather J, Nicholl J, Cleghorn L. Navigation delivery models and roles of navigators in primary care: a scoping literature review. BMC Health Serv Res. 2018;18(1):96. Published 2018 Feb 8. doi:10.1186/s12913-018-2889-0.

39. Courtin E, Jemiai N, Mossialos E. Mapping support policies for informal carers across the European Union. Health Policy. 2014;118(1):84-94. doi:10.1016/j.healthpol.2014.07.013.

40. Brault MA, Brewster AL, Bradley EH, Keene D, Tan AX, Curry LA. Links between social environment and health care utilization and costs. J Gerontol Soc Work. 2018;61(2):203-20. doi:10.1080/01634372.2018.1433737. 